Article

\title{
Repair of the Orbital Wall Fractures in Rabbit Animal Model Using Nanostructured Hydroxyapatite-Based Implant
}

\author{
Sinziana Gradinaru ${ }^{1, \dagger}$, Laura Madalina Popescu ${ }^{2,+}$, Roxana Mioara Piticescu ${ }^{2, *}$, \\ Sabina Zurac ${ }^{3, *}$, Radu Ciuluvica ${ }^{4}$, Alexandrina Burlacu ${ }^{5, \dagger}{ }^{+}$, Raluca Tutuianu ${ }^{5}$, \\ Sorina-Nicoleta Valsan ${ }^{2}$, Adrian Mihail Motoc ${ }^{2}$ and Liliana Mary Voinea ${ }^{1}$ \\ Received: 7 December 2015; Accepted: 29 December 2015; Published: 7 January 2016 \\ Academic Editor: Andrea Danani \\ 1 Ophthalmology Department, "Carol Davila" University of Medicine and Pharmacy, 050474 Bucharest, \\ Romania; sanzinici@yahoo.com (S.G.); voineamliliana@yahoo.com (L.M.V.) \\ 2 National R \& D Institute for Non-ferrous and Rare Metals, 077145 Ilfov, Romania; \\ mpopescu@imnr.ro (L.M.P.); svalsan@imnr.ro (S.-N.V.); amotoc@imnr.ro (A.M.M.) \\ 3 Pathology Department, "Carol Davila” University of Medicine and Pharmacy, 050474 Bucharest, Romania \\ 4 Anatomy Department, "Carol Davila” University of Medicine and Pharmacy, 050474 Bucharest, Romania; \\ raduciuluvica@yahoo.com \\ 5 Institute of Cellular Biology and Pathology "Nicolae Simionescu", 050568 Bucharest, Romania; \\ sanda.burlacu@icbp.ro (A.B.); raluca.tutuianu@icbp.ro (R.T.) \\ * Correspondence: roxana@imnr.ro (R.M.P.); sabina_zurac@yahoo.com (S.Z.); \\ Tel.: +40-21-3522048 (ext. 113) (R.M.P.); +40-720-538263 (S.Z.); Fax: +40-21-3522049 (R.M.P.) \\ + These authors contributed equally to this work.
}

\begin{abstract}
Cellular uptake and cytotoxicity of nanostructured hydroxyapatite (nanoHAp) are dependent on its physical parameters. Therefore, an understanding of both surface chemistry and morphology of nanoHAp is needed in order to be able to anticipate its in vivo behavior. The aim of this paper is to characterize an engineered nanoHAp in terms of physico-chemical properties, biocompatibility, and its capability to reconstitute the orbital wall fractures in rabbits. NanoHAp was synthesized using a high pressure hydrothermal method and characterized by physico-chemical, structural, morphological, and optical techniques. X-ray diffraction revealed HAp crystallites of $21 \mathrm{~nm}$, while Scanning Electron Microscopy (SEM) images showed spherical shapes of HAp powder. Mean particle size of HAp measured by DLS technique was $146.3 \mathrm{~nm}$. Biocompatibility was estimated by the effect of HAp powder on the adhesion and proliferation of mesenchymal stem cells (MSC) in culture. The results showed that cell proliferation on powder-coated slides was between $73.4 \%$ and $98.3 \%$ of control cells (cells grown in normal culture conditions). Computed tomography analysis of the preformed nanoHAp implanted in orbital wall fractures, performed at one and two months postoperative, demonstrated the integration of the implants in the bones. In conclusion, our engineered nanoHAp is stable, biocompatible, and may be safely considered for reconstruction of orbital wall fractures.
\end{abstract}

Keywords: nanostructured HAp; mesenchymal stem cells; orbital wall fracture; implant

\section{Introduction}

Bone graft materials are widely used for filling bone defects, mostly by orthopedists and oral surgeons; the indications are variable, ranging form fractures to tumors. Lately, several types of biomaterials have been used for grafting, either natural or synthetic, each type of graft presenting specific advantages and disadvantages. In the last ten years, various types of individual implants, 
such as high-density polyethylene (HDPE), titanium, hydroxyapatite, polydioxanone, and polylactic acid/polyglycolic acid implants have been used for the reconstruction of orbital fractures [1-4]. This therapeutic reconstruction is very promising due to the excellent anticipated ophthalmologic results [3,5-7]. However, there is still no implant able to substitute the functional properties of missing or diseased bone and to sustain and assist cell proliferation and anchorage to the existing bone [8]. Once these requirements are achieved, they will lead to osseointegration and will ensure optimal biomechanical properties of the bone/biomaterial implant [8-10].

It is well known that hydroxyapatite (HAp) is one of the most stable bioactive ceramic materials, able to integrate within living tissues and generate excellent biocompatibility. It has been shown that HAp can stimulate the bone growth through osteoconduction mechanism without causing any local or systemic toxicity, inflammation, or body rejection [11,12]. Nontoxicity, lack of inflammatory and immune responses, and high bioactivity makes HAp one of the most used and recommended materials for correction of bone defects.

Recent studies [11-16] reported that the morphology of HAp is very important for its successful use in bone regeneration. Thus, HAp was synthesized in different shapes, such as microspheres, plates, nanorods, or nanofibers. Porosity, surface roughness, and mechanical properties are also crucial for HAp use in bone regeneration, as well as the sintering behavior, which can affect several mechanical properties and is directly related to other physical parameters such as particle size and shape [17]. Cellular uptake and cytotoxicity of nanostructured hydroxyapatite (nanoHAp) are dependent on these parameters (size, shape, crystallinity) [18]. It has been shown that nanoHAp might impact cell behavior at both the membrane and the intracellular level. Increased amounts of intracellular calcium may lead to cytotoxic effects as reported in several studies [18]. Therefore, both surface chemistry and morphology are needed to be well understood to anticipate in vivo behavior of the bone implant.

NanoHAp powders make the sinterability easier and enhance densification due to an increased surface area:size ratio, which makes them ideal substitutes for natural bone [19]. Up to now, various wet chemical routes in aqueous or non-aqueous solution systems have been employed to synthesize nanostructured HAp [12,20,21], such as hydrothermal [22,23], chemical precipitation [24,25], wet chemical [26,27], and sol-gel methods [28,29].

NanoHAp is currently used as drug delivery material, bone defect filler, or for oral care products in the form of a paste or suspension [18]. One of the potential applications of nanoHAp could be reconstruction of the orbital wall fractures. We report here the synthesis of nanostructured HAp using our previous experience in this field of hydrothermal method in high pressure conditions [30-34], for reconstruction of the orbital wall fractures. To our knowledge, this is the first study reporting the use of a nanostructured HAp for orbital wall fracture reconstruction.

Previous studies in the field of orbital wall regeneration demonstrated the potential of calcium phosphate cement as a useful biomaterial in the reconstruction of the anterior orbital region in a sheep model [4] and ultrahigh molecular weight polyethylene implant as a material for precise reconstruction of orbital wall defects in human patients [3]. A step forward comparing to our previous work [34] is tailoring the experimental parameters in order to obtain a material with controlled structure and properties. The aim of the paper is to characterize engineered nano-hydroxyapatite in terms of its physicochemical properties, in vitro behavior, and interactions with living systems for reconstruction of orbital wall fractures.

\section{Results and Discussion}

Obtaining HAp by hydrothermal method has several advantages, such as aqueous reaction medium, nanocrystalline and high purity materials with controlled morphology, and low energy consumption. Physicochemical, structural, and morphological characterizations of nanopowders and sintered pellets were performed in order to have a better understanding of the HAp interaction with living systems, and are presented as follows. 


\subsection{Physicochemical Characterization}

Calcium and phosphorus content determined by quantitative analysis, as well as specific surface area and average pore diameter are presented in Table 1.

Table 1. Chemical analysis, BET ${ }^{1}$ surface area and pore size. HAp: Hydroxyapatite.

\begin{tabular}{cccccc}
\hline Sample Type & Ca (\%) & $\mathbf{P ~ ( \% )}$ & Ca:P Ratio & $\begin{array}{c}\text { BET Specific } \\
\text { Surface Area }\left(\mathbf{m}^{2} / \mathbf{g}\right)\end{array}$ & $\begin{array}{c}\mathbf{B J H}^{\mathbf{2}} \text { Adsorption Average } \\
\text { Pore Diameter (nm) }\end{array}$ \\
\hline $\begin{array}{c}\text { HAp nanopowder } \\
\begin{array}{c}\text { HAp sintered at } \\
800^{\circ} \mathrm{C} / 30 \mathrm{~min}\end{array}\end{array}$ & 39.34 & 19.15 & 1.59 & 37.11 & 11.80 \\
\hline
\end{tabular}

${ }^{1}$ Brunauer-Emmett-Teller (BET) Surface Area Analysis; ${ }^{2}$ Barrett-Joyner-Halenda (BJH) Pore Size and Volume Analysis.

\subsection{Structural Characterization (X-Ray Diffraction)}

The phase purity and structure were investigated by X-ray diffraction (XRD) analysis. As depicted in Figure 1, XRD analysis revealed a single phase corresponding to $\mathrm{Ca}{ }_{5}\left(\mathrm{PO}_{4}\right)_{3} \mathrm{OH}$ with a hexagonal structure, P63/m (176) space group, according to PDF Reference 00-009-0432 (ICDD database, Powder Diffraction File, edited by International Centre for Diffraction Data 2006). Cell parameters were: $a=9.42876 \AA, c=6.88582 \AA$, suggesting a preferential growth in the (0 0 l) direction. Crystallite size (Scherrer) was $21.52 \mathrm{~nm}$ in the case of HAp powder and $42 \mathrm{~nm}$ in the case of sintered pellet.
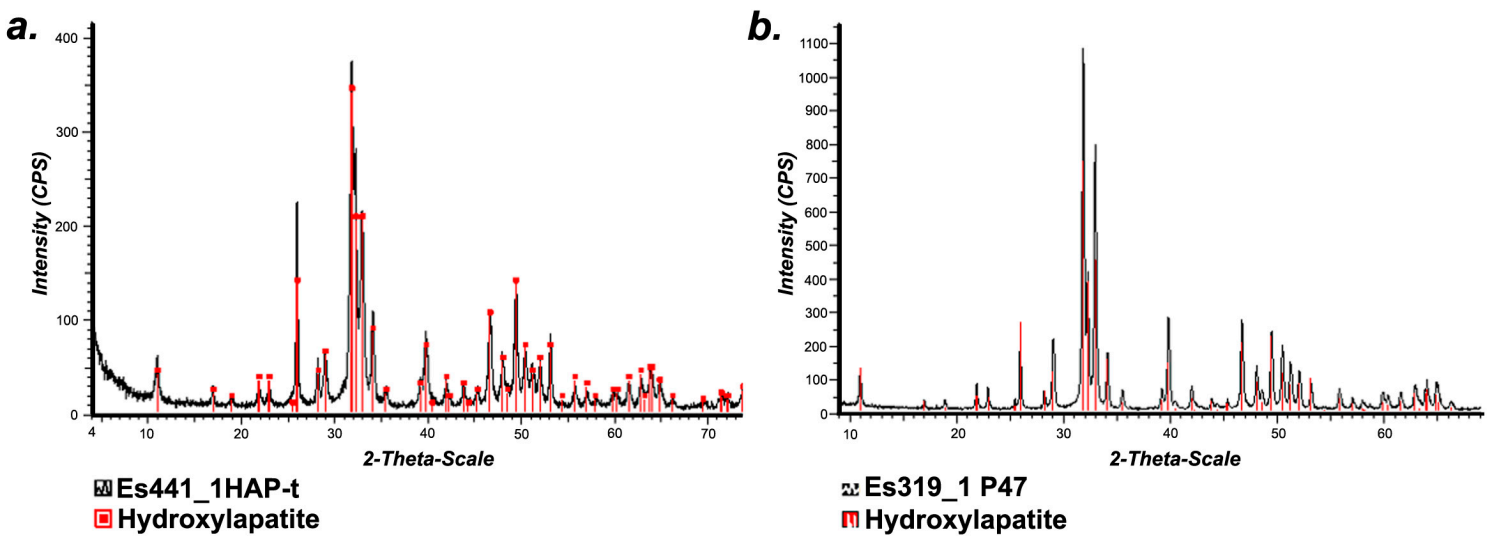

Figure 1. (a) X-ray diffractogram of HAp nanopowder; (b) X-ray diffractogram of HAp sintered at $800{ }^{\circ} \mathrm{C} / 30 \mathrm{~min}$.

\subsection{Morphological Characterization (SEM Analysis)}

The SEM image in Figure 2a shows spherical shape of HAp powder prepared by hydrothermal method and granulated in spray dryer. Large agglomerates can be observed with diameters between 2 and $10 \mu \mathrm{m}$. After sintering (Figure 2b), compacting and compression deformation of the particles is observed. Diameters of the compressed particles range between 40 and $80 \mathrm{~nm}$. 

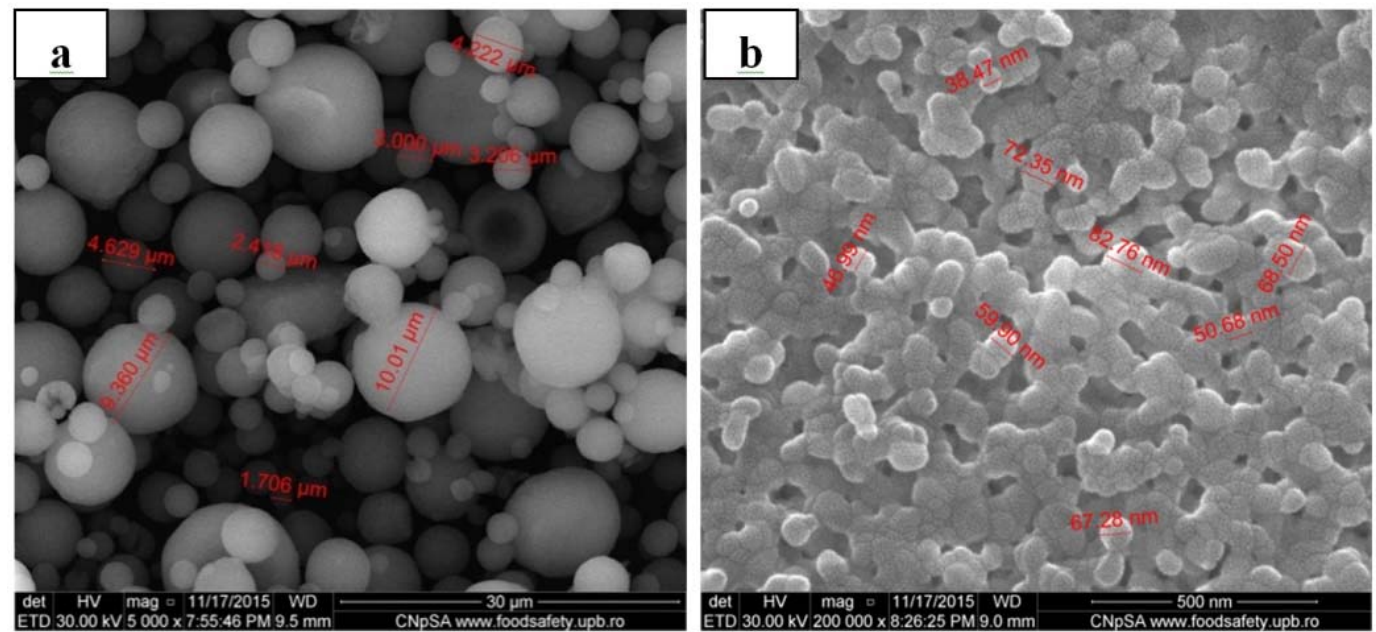

Figure 2. (a) Scanning Electron Microscopy (SEM) image of HAp nanopowder; (b) SEM image of HAp sintered at $800{ }^{\circ} \mathrm{C} / 30 \mathrm{~min}$.

\subsection{Particle Size Distribution}

Particle size distribution by intensity of the nanoHAp powder is depicted in Figure 3. Average particle size is $146.3 \mathrm{~nm}$, with a polydispersity index of $6.1 \%$, which suggests a narrow distribution of mean hydrodynamic size.

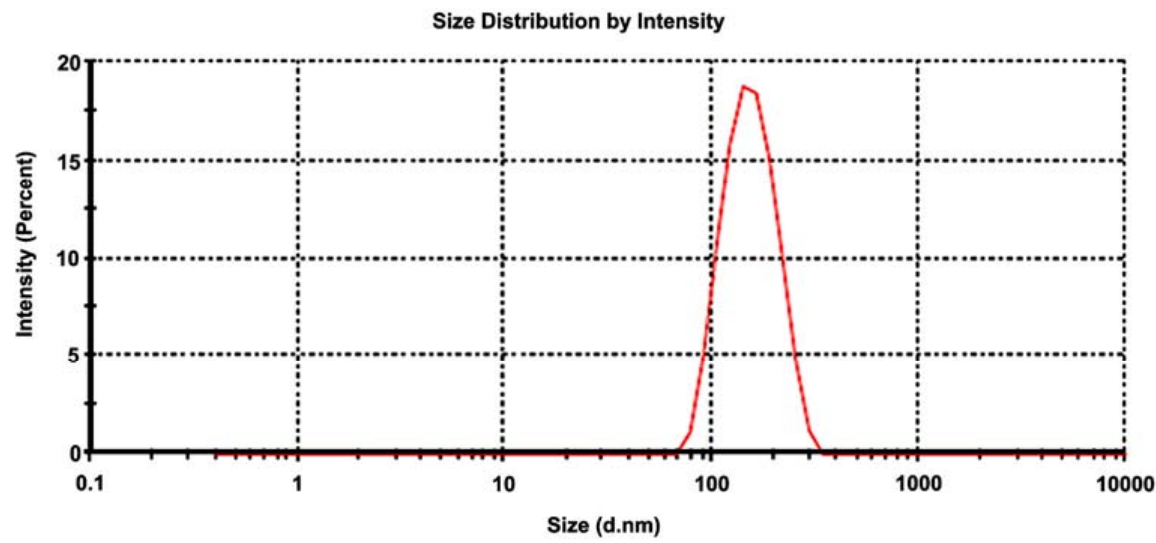

Figure 3. Particle size distribution of HAp nanopowder.

\subsection{In Vitro Test}

The proliferation of mesenchymal stem cells (MSC) in the presence of HAp was analyzed by incubation of the adhered cells ( $24 \mathrm{~h}$ after seeding) with various dilutions of HAp for four days in culture. The results showed that the two compounds had no cytotoxic effects on cells. Moreover, at higher dilutions (i.e., 1/100 and 1/50), both solutions (HAp1s with $\mathrm{pH}=1.33$, and HAp2s with $\mathrm{pH}=1.88$ ) even stimulated the proliferation of MSC in culture in comparison to normally cultured cells. The increase in MSC proliferation obtained by cell culturing in the presence of low amounts of nanoHAp can only be explained by cell activation. Although the mechanisms leading to such cell activation remains unknown in the absence of other in-depth studies, several other papers have previously reported that stressing environmental conditions (e.g., transient low-pH stressor) might impact the adult stem cells' behavior by activating several stem cell-specific signaling pathways [35].

However, the presence of HAp solutions at smaller dilutions in culture medium (i.e., $1 / 20$ and $1 / 10$ ) resulted in a decrease in cell proliferation (Figure 4). This effect was more pronounced in the 
presence of HAp2s ( $\mathrm{pH}=1.31$ ), which is suggested to be a result of acidification of growth medium rather than a direct cytotoxic effect of HAp itself.

When MSC were grown directly on powder HAp-coated slides, cell adhesion and proliferation was between $73.4 \%$ and $98.3 \%$ (with a mean of $81.8 \% \pm 11.7 \%, n=6$ ) of cells cultured on uncoated slides, once again confirming the biocompatibility of these materials with in vitro cells.

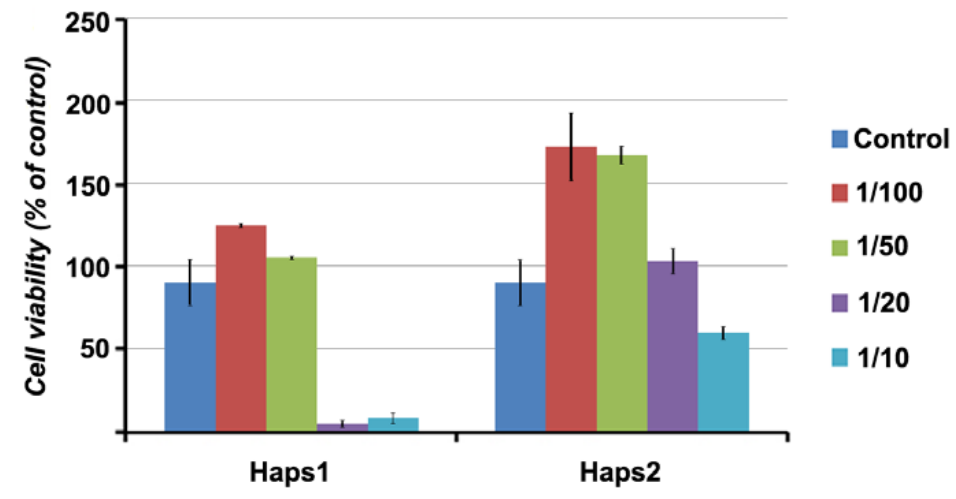

Figure 4. Mesenchymal stem cell (MSC) proliferation in the presence of HAp solubilized in phosphorous acid 5\% ( $\mathrm{pH}=1.31$, HAp1s) or phosphorous acid 1\% ( $\mathrm{pH}=1.88$, HAp2s). Results are given as mean \pm standard deviation (S.D.) of the cell viability expressed as percentage of control cells (cells incubated in normal growth medium in the absence of HAp).

\subsection{In Vivo Test}

Computed tomography (CT) analyses of nanostructured hydroxyapatite implant performed one and two months postoperative revealed time-dependent increasing densities (measured in Hounsfield Units), which are showed in Table 2.

Table 2. Maximum density values in Hounsfield Units (HU) of the implant and surrounding tissues regarding normal orbital osseous density.

\begin{tabular}{lccc}
\hline Male Rabbit & $\begin{array}{c}\text { Maximum Density of the Implant } \\
\text { One Month Postoperative (HU) }\end{array}$ & $\begin{array}{c}\text { Maximum Density of the } \\
\text { Implant Two Months } \\
\text { Postoperative (HU) }\end{array}$ & $\begin{array}{c}\text { Normal Orbital } \\
\text { Density (HU) }\end{array}$ \\
\hline Rabbit 1 & 202 & 400 & 900 \\
Rabbit 2 & 315 & 450 & 1000 \\
Rabbit 3 & 250 & 402 & 1120 \\
Rabbit 4 & 309 & 409 & 940 \\
\hline \multicolumn{5}{c}{ Maximum Density of the } & Maximum Density of the \\
Male Rabbit & Surrounding Fibrovascular Tissue & Tissue Two Months & Normal Orbital \\
\multicolumn{5}{c}{ Postoperative (HU) } & \\
Rabbit 1 & One Month Postoperative (HU) & 70 & 900 \\
Rabbit 2 & 40 & 72 & 1000 \\
Rabbit 3 & 50 & 75 & 1120 \\
Rabbit 4 & 40 & 70 & 940 \\
\hline
\end{tabular}

The osseous reconstruction images obtained by 3D CT of the animals before and after surgery are presented in Figure 5 (before surgery), Figure 6 (at one month after surgery) and Figure 7 (at two months after surgery). Figures 6 and 7 show the implant of nanoHAp and the surrounding fibrovascular tissue at one and two months postoperative, respectively.

The red arrow marks the implant of nanoHAp. In rabbit 1 (Figure 6), a cleavage plan between the implant and the bone could be noted at one month postoperative, proved by the existence of a surrounding fibrovascular tissue with low density $(\mathrm{HU}=40)$. This cleavage plan was also noted in 
rabbit 2 between the implant and the bone demonstrated by the presence of a fibrovascular tissue with medium density $(\mathrm{HU}=50)$. For rabbit 3, a large cleavage plan was noted between the implant and the bone. A low density of the surrounding fibrovascular tissue $(40 \mathrm{HU})$ was observed. The explanation might be related to the great difference between the bone density $(H U=1120)$ and fibrovascular density. The cleavage plan was absent in rabbit 4 , as the surrounding fibrovascular tissue had a high density $(\mathrm{HU}=60)$.

At two months postoperative, the cleavage plan was absent in rabbit 1 (Figure 7), but there was still a low-density surrounding fibrovascular tissue. In rabbit 2, there was no cleavage between the implant (red arrow) and the bone. CT scans revealed that the implant had a lower density than the bone at one month post-surgery. However, it progressively increased, so that at two months post-surgery the density of implant appeared similar or even higher than that of the fibrous tissue.

A persistence of a cleavage plan between the implant and the bone, demonstrated by the presence of a low-density fibrovascular tissue $(\mathrm{HU}=40)$, was remarked in two animals at one month postoperative. One of the subjects presented a higher cleavage plan, a possible explanation being related to the greater difference between the density of the normal bone (HU = 1120) and fibrovascular tissue. At two months postoperative the implant had a higher density and the implant was integrated in the osseous tissue.

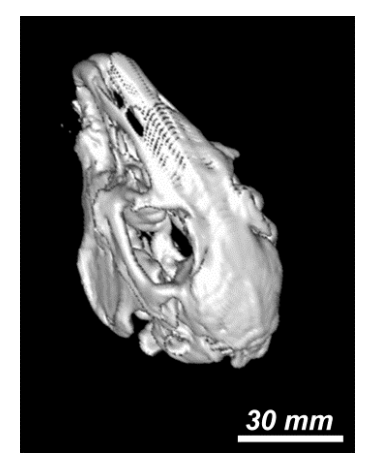

Figure 5. 3D computed tomography $(\mathrm{CT})$ reconstruction image of the animal model before surgery. Scale was estimated based on corresponding 2-D image.
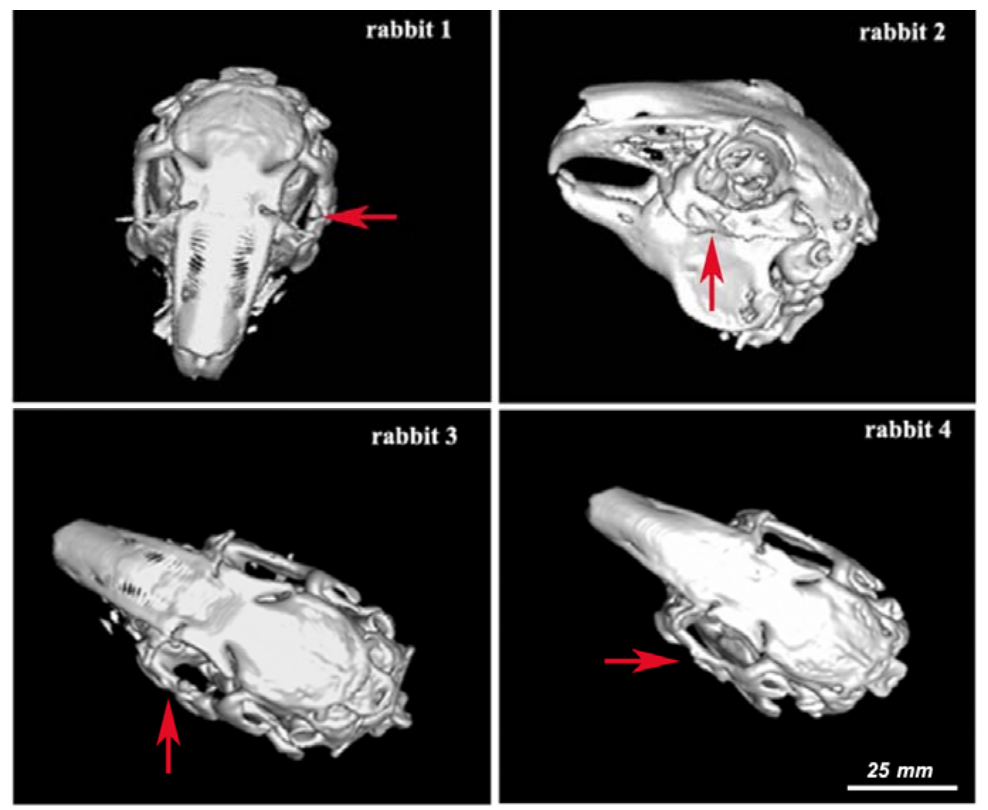

Figure 6. 3D CT osseous reconstruction images at one month postoperative for rabbits $1-4$. Scale was estimated based on corresponding 2-D image. 

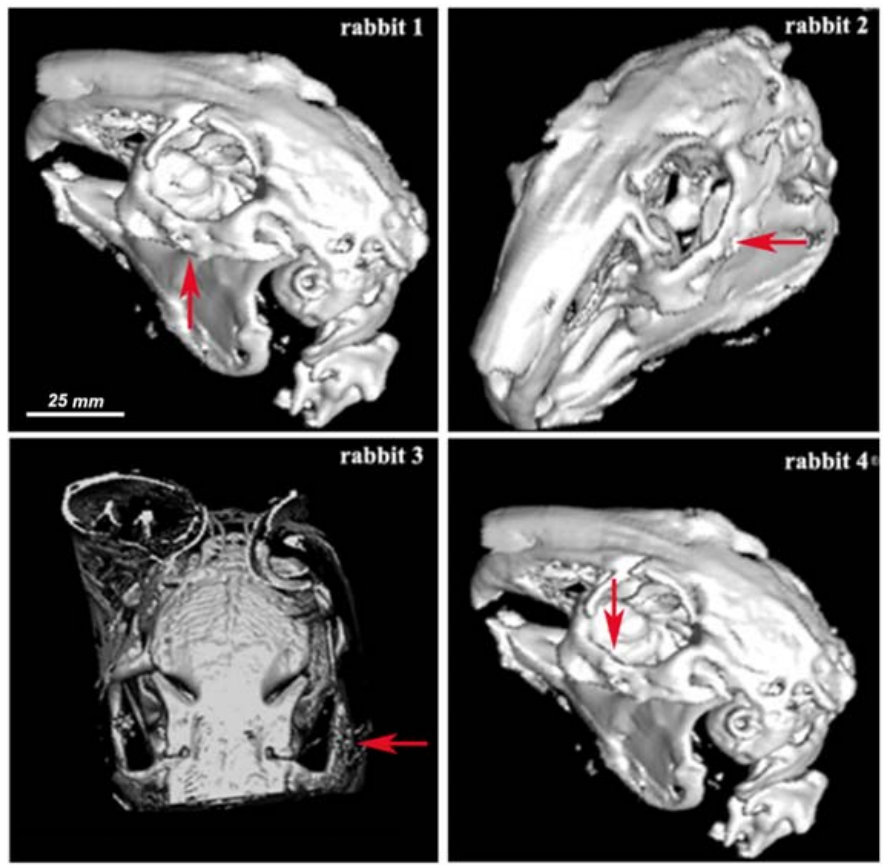

Figure 7. 3D CT osseous reconstruction images at two months postoperative for rabbits $1-4$. Scale was estimated based on corresponding 2-D image.

The histological analyses showed good integration of the implant in the host tissue, proved by fibrovascular ingrowth between the implant pores. Furthermore, hematoxilin-eosin staining (Figure 8) revealed the presence of the osteoclasts (white arrowheads) with large nuclei at the interface between HAp implant and bone, which demonstrated the degradation of HAp in order to allow the development of new bone.

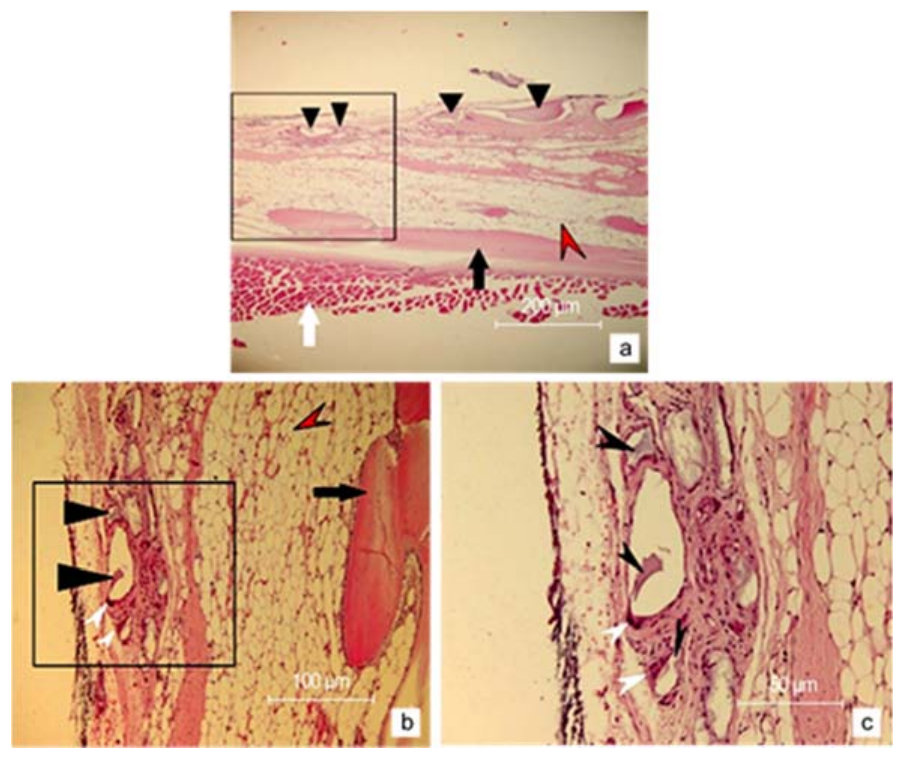

Figure 8. (a) Microscopic aspects of HAp implant two months after implantation, as revealed by hematoxilin eosin staining (the magnification is $10 \times$ ); (b) Detailed image of the inset in figure (a) at $20 \times$ magnification; (c) Detailed image of the inset in figure (b) at $40 \times$ magnification. Black arrowheads mark HAp implant. Black arrows mark the osseous tissue. White arrowheads mark osteoclasts. White arrows mark the inferior rectus muscle. Red arrowheads mark the adipose tissue adjacent to bone structure. 
Immunohistochemical analysis revealed the presence of many vascular structures delineated by $\mathrm{CD} 31^{+}$-endothelial cells, indicating good vascularization of the implant (Figure 9). In conclusion, our engineered nanoHAp is stable, biocompatible, and may be safely considered for reconstruction of orbital wall fractures.

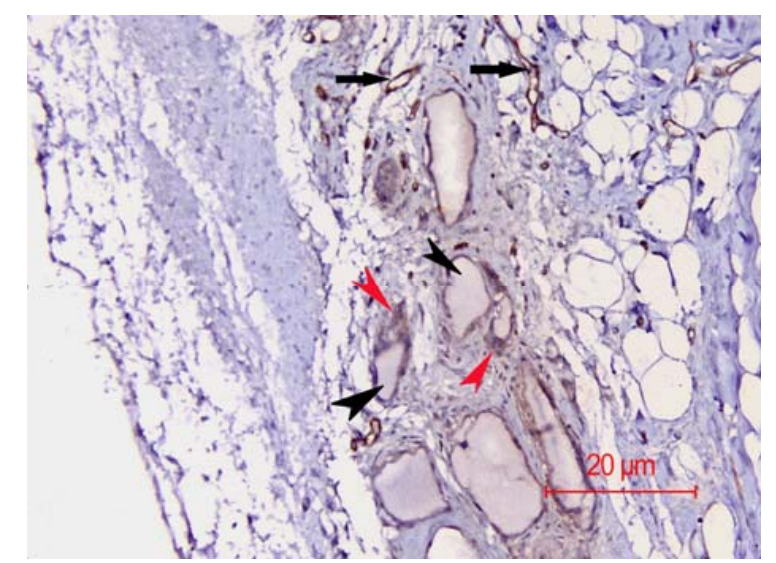

Figure 9. CD31 immunohistochemical staining of the implant. Black arrowheads mark the vascular structures, black arrows mark the CD31-positive cells delineating the vascular structures. Red arrowheads mark the osteoclasts at the interface between the implant and bone. The magnification is $100 \times$.

\section{Experimental Section}

\subsection{Hydrothermal Synthesis of NanoHAp Powder}

Analytical grade precursors, namely calcium nitrate and ammonium dihydrogen phosphate, were solubilized in water under a strict $\mathrm{pH}$ control, adding ammonium hydroxide as a mineralizing agent. The aqueous suspension thus obtained was transferred to the Teflon vessel of a closed autoclave (Berghof, Germany) equipped with cooling system, for hydrothermal synthesis at $150{ }^{\circ} \mathrm{C} / 100 \mathrm{barr}$. The resulted suspension was processed by spray dryer (LabPLANT, Filey, UK). The HAp nanopowder was further evaluated for physical and chemical properties, and the in vitro behavior was established by interaction with mouse bone marrow-derived MSC in culture.

\subsection{Manufacturing of NanoHAp-Based Sintered Pellets}

NanoHAp powder, prepared as described above, was mixed with 3\% poly(vinyl alcohol) (PVA) as binder and further pressed at $0.5 \mathrm{~N} / \mathrm{m}^{2}$ using a manual hydraulic press (Specac LTD., Orpington, UK). The resulting pellets, having $6 \mathrm{~mm}$ diameter and $1.3 \mathrm{~mm}$ height were sintered in air at $800{ }^{\circ} \mathrm{C}$ for $30 \mathrm{~min}$, using a CARBOLITE chamber furnace (Hope Valley, UK). Sintering parameters were chosen to provide a specific porosity to the final material (hydroxyapatite implant). These pellets were first evaluated for physical and chemical properties, and then for biocompatibility prior to implantation in rabbits with preformed orbital wall defects for evaluation of their biological effects.

\subsection{Characterization of NanoHAp}

\subsubsection{Physico-Chemical Characterization}

Chemical composition: Calcium and phosphorus contents in HAp nanopowders were determined by atomic absorption spectroscopy (AAS ZEEnit 700, Analytic Jena AG, Jena, Germany) and inductively-coupled plasma ICP spectrometry (Spectroflame P, Kleve, Germany), respectively.

Specific surface area and porosity measurements: Brunauer-Emmett-Teller (BET) surface area analysis was performed using GEMINI 2380 equipment (Micromeritics Company, Mönchengladbach, 
Germany) in the following working conditions: nitrogen atmosphere, equilibration time $5 \mathrm{~s}$, saturation pressure $799.570 \mathrm{mmHg}$.

\subsubsection{Structural Characterization (XRD Analysis)}

In order to identify the pattern of X-ray diffraction (XRD) for nanoHAp powder, we used a Bruker D8 Advance diffractometer (Karlsruhe, Germany) with monochromatic $\mathrm{CuK} \alpha$ radiation (scanning in $2 \theta$ range $=4-74^{\circ}$; step size of 0.020 every $2 \mathrm{~s}$ ).

\subsubsection{Morphological Characterization (SEM Analysis)}

Morphological observations were carried out by scanning electron microscopy (SEM) using a Quanta Inspect F50 FEG microscope (resolution $1.4 \mathrm{~nm}$ ) equipped with energy dispersive X-ray detector (EDAX), (FEI Company, Eindhoven, The Netherlands). Particle size measurements have been performed through DigitalMicrograph ${ }^{\mathrm{TM}}$, Gatan Inc. (Pleasanton, CA, USA) image acquisition and processing software.

\subsubsection{Particle Size Distribution}

Particle size distribution was performed by DLS technique, using Zetasizer Nano ZS 90 laser granulometer, Malvern Instruments (Worcestershire, UK), domain 0.6-3.0 $\mu \mathrm{m}$, temperature range $20-90{ }^{\circ} \mathrm{C}$, dispersion type wet, and specialized software.

\subsection{Evaluation of Biocompatibility by In Vitro Cell Culture Studies}

The in vitro behavior of the nanostructured HAp, either as powder layered on the surface of culture cover slides or solubilized in phosphorous acid solution, was assessed by interaction with mouse-derived mesenchymal stem cells (MSC). To this aim, cells were directly seeded onto nanoHAp-coated cover slides and grown for 5 days before viability assessment by 3-(4,5-dimethylthiazol-2-yl)-2,5-diphenyltetrazolium bromide (MTT) assay. The biocompatibility of HAp solubilized in phosphorous acid was evaluated on MSC seeded on 96-well plates (2000 cells/well) in DMEM supplemented with 10\% MSC-qualified FCS (fetal calf serum, Invitrogen, Carlsbad, CA, USA). Twenty-four hours later, the medium was replaced with growth medium in the presence of various dilutions of HAp solutions (HAp1s, with a $\mathrm{pH}$ of 1.38 and HAp2s with a $\mathrm{pH}$ of 1.88) covering the range between $1 / 5$ and $1 / 100$. Cell proliferation was evaluated by MTT assay after 5 days of culture, which represented the period cells usually need to get to confluence.

\subsection{In Vivo Test}

HAp sintered pellets were used as implants in four male rabbits. Before implantation, two bridges were created on the surface of the implants to allow the periostal attachment intraoperatory through a 9-0 vicryl suture.

\subsubsection{Animal model}

All the procedures were approved by the Ethic Committee of University of Medicine and Pharmacy, code PO-35-F-03/nr.33/08.10.2014, in accordance with the European Convention for the protection of vertebrate animals used for experimental or other scientific purposes (Strasbourg 18.03.1986) and The Directive 2010/63/UE.

\subsubsection{Surgical Intervention Methodology}

Four male rabbits (Oryctolagus cuniculus) with age around 12 months were weighed then anesthetized by intramuscular administration of Xilazin (Xilazin Bio, Maravet Animal Health) $0.15 \mathrm{~mL} / \mathrm{kg}$ body weight, and after $10 \mathrm{~min}$ by intravenous administration of ketamine (Ketaminol10, MSD Animal Health) $0.1 \mathrm{~mL} / \mathrm{kg}$ body weight. A volume of $0.15 \mathrm{~mL}$ adrenaline 1/100.000 was 
administered in lateral cantus and inferior conjunctival cul de sac to induce proper local hemostasis. After induction of the general anesthesia, lateral cantothomy and cantholysis were performed and a tractor 4-0 silk thread was passed through the inferior lid to allow visualization of the inferior orbital wall. An inferior conjunctival incision was made in the inferior fornix and the orbicular muscle and orbitary septum were dissected out through inferior orbital margin. After opening the orbitary septum, the inferior rim orbital periosteum was isolated and a $0.5 \mathrm{~cm}$ diameter orbital defect was produced in the inferior rim, by using a stomatologic trephine (Figure 10).

The nanostructured implant was placed in the defect and attached to the orbital periosteum with 9-0 vicryl sutures. At the end, the residual defect was filled with nanoHAp powder. The orbital periosteum was reattached and the orbitary septum, the conjunctiva, and the lateral cantus were closed. A $0.3 \%$ tobramycin and $0.1 \%$ dexamethasone ointment (Tobradex, Alcon, Fort Worth, TX, USA) was applied and subcutaneous enrofloxacine (Ganadexil Enro 5\%, Industrial Veterinaria SA, Barcelona, Spain) $0.5 \mathrm{~mL} / \mathrm{kg}$ bw/day was given for 5 days.
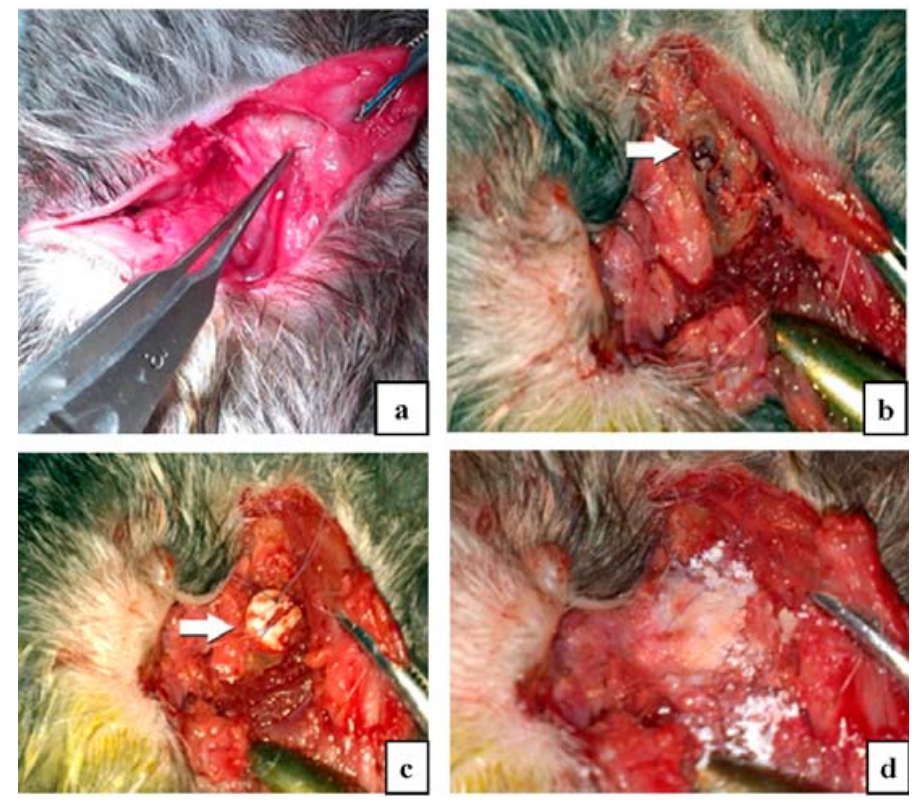

Figure 10. Intra-operatory aspect: (a) transconjunctival approach and lateral cantothomy facilitate the inferior rim periosteal elevation; (b) the preformed osseous defect in the inferior orbital wall of $0.5 \mathrm{~cm}$ diameter (white arrow); (c) the orbital implant placed in the defect area and sutured to the periosteum; (d) the rest of the defect covered with hydroxyapatite powder.

\subsubsection{Postoperative Care}

Postoperative daily ophthalmological assessment consisting of slit lamp evaluation was conducted for 10 days, and then ophthalmologic evaluations were performed every third day for a month. At one and two months post-surgery, all subjects underwent CT exams under general anesthesia in order to monitor the implant integration. CT scans were performed with a computer tomography Siemens and SOMATOM-SIEMENS software version syngoHEAD CT 2007E. 3D reconstruction was obtained using 3D RECON software. HeadSpi/Fine 0.6-2.4 Sections were used for the orbital examinations.

CT investigation protocol consisted of:

(1) Topogram (selection of the region of interest).

(2) Initial acquisition of 2.4 (avoiding movement artifacts by shortening the exposure and acquisition time).

(3) Reconstruction (HeadSecv 1.2, Headsecv 0.6 and SSD (3D), frontal and sagittal multiplanar reconstruction).

(4) Hounsfield units assessment of the implant and related tissues. 
The bone fragment containing the implant was harvested two months after surgery by a similar surgical intervention with a drilling procedure after opening the orbital septum for bone harvesting. The bone was placed in $10 \%$ formaldehyde and processed for paraffin embedding and histopathology/immunohistochemistry analysis.

\section{Conclusions}

Crystalline nanoHAp with crystallite size of $21.52 \mathrm{~nm}$ was prepared using hydrothermal method in one step, without any further thermal treatment of the obtained powder. In vitro test showed that HAp had good biocompatible properties, both as solutions with various dilutions and as powder-coated slides. Moreover, at higher dilutions (i.e., 1/100 and 1/50), HAp solutions even stimulated the proliferation of MSC in culture, in comparison to normally cultured cells. MSC adhesion and proliferation was between $73.4 \%$ and $98.3 \%$ in the case of powder-coated slides.

The CT analysis of the preformed nanoHAp implant for repairing of the orbital wall fractures showed a good integration of the implant in the bone at two months postoperative, thus demonstrating that our engineered nanoHAp is stable, biocompatible, and may be safely considered for reconstruction of orbital wall fractures.

Acknowledgments: Contract No. 114/2014 ORBIMPLANT is gratefully acknowledged for financial support. The authors thank to Eugeniu Vasile-University Politehnica Bucharest, Romania for performing Scanning Electron Microscopy (SEM) analysis and eng. Paul Stanciu-National R \& D Institute for Non-ferrous and Rare Metals, for powder processing by spray dryer. The authors from National R \& D Institute for Nonferrous and Rare Metals, Romania used the infrastructure purchased in the frame of Structural Funds Project-HighPTMet (ctr.253/28.09.2010).

Author Contributions: S.G., L.M.P., R.M.P., R.C., A.B. and L.M.V. designed the experiments. S.G., L.M.P., R.M.P. and A.B. prepared the manuscript. A.B and R.T. performed in vitro experiments. R.C. performed in vivo experiments. S.Z. performed CT measurements. S.N.V prepared sintered pellets and performed particle size distribution measurements. A.M.M. interpreted the results. All authors read and approved the final manuscript.

Conflicts of Interest: The authors declare no conflict of interest.

\section{References}

1. Schon, R.; Metzger, M.C.; Zizelmann, C.; Weyer, N.; Schmelzeisen, R. Individually preformed titanium mesh implants for a true-to-original repair of orbital fractures. Int. J. Oral Max. Surg. 2006, 35, 990-995. [CrossRef] [PubMed]

2. Kozakiewicz, M.; Elgalal, M.; Loba, P.; Komunski, P.; Arkuszewski, P.; Broniarczyk-Loba, A.; Stefanczyk, L. Clinical application of 3D pre-bent titanium implants for orbital floor fractures. J. Cranio Maxill. Surg. 2009, 37, 229-234. [CrossRef] [PubMed]

3. Kozakiewicz, M.; Elgalal, M.; Walkowiak, B.; Stefanczyk, L. Technical concept of patient-specific, ultrahigh molecular weight polyethylene orbital wall implant. J. Cranio Maxill. Surg. 2013, 41, 282-290. [CrossRef] [PubMed]

4. Sinikovic, B.; Kramer, F.J.; Swennen, G.; Lubbers, H.T.; Dempf, R. Reconstruction of orbital wall defects with calcium phosphate cement: Clinical and histological findings in a sheep model. Int. J. Oral Max. Surg. 2007, 36, 54-61. [CrossRef] [PubMed]

5. Kozakiewicz, M.; Elgalal, M.; Piotr, L.; Broniarczyk-Loba, A.; Stefanczyk, L. Treatment with individual orbital wall implants in humans-1-Year ophthalmologic evaluation. J. Cranio Maxill. Surg. 2011, 39, 30-36. [CrossRef] [PubMed]

6. Loba, P.; Kozakiewicz, M.; Elgalal, M.; Stefanczyk, L.; Broniarczyk-Loba, A.; Omulecki, W. The use of modern imaging techniques in the diagnosis and treatment planning of patients with orbital floor fractures. Med. Sci. Monit. 2011, 17, CS94-CS98. [CrossRef]

7. He, D.; Li, Z.; Shi, W.; Sun, Y.; Zhu, H.; Lin, M.; Shen, G.; Fan, X. Orbitozygomatic fractures with enophthalmos: Analysis of 64 cases treated late. J. Oral Maxil. Surg. 2012, 70, 562-576. [CrossRef] [PubMed]

8. Fricia, M.; Passanisi, M.; Salamanna, F.; Parrilli, A.; Giavaresi, G.; Fini, M. Osteointegration in custom-made porous hydroxyapatite cranial implants: From reconstructive surgery to regenerative medicine. World Neurosurg. 2015, 84. [CrossRef] [PubMed] 
9. Fernandez-Yague, M.A.; Abbah, S.A.; McNamara, L.; Zeugolis, D.I.; Pandit, A.; Biggs, M.J. Biomimetic approaches in bone tissue engineering: Integrating biological and physicomechanical strategies. Adv. Drug Deliver. Rev. 2015, 84, 1-29. [CrossRef] [PubMed]

10. Tevlin, R.; McArdle, A.; Atashroo, D.; Walmsley, G.G.; Senarath-Yapa, K.; Zielins, E.R.; Paik, K.J.; Longaker, M.T.; Wan, D.C. Biomaterials for craniofacial bone engineering. J. Dent. Res. 2014, 93, 1187-1195. [CrossRef] [PubMed]

11. Chen, J.; Wang, Z.; Wen, Z.; Yang, S.; Wang, J.; Zhang, Q. Controllable self-assembly of mesoporous hydroxyapatite. Colloids Surf. B 2015, 127, 47-53. [CrossRef] [PubMed]

12. Mohandes, F.; Salavati-Niasari, M.; Fathi, M.; Fereshteh, Z. Hydroxyapatite nanocrystals: Simple preparation, characterization and formation mechanism. Mat. Sci. Eng. C 2014, 45, 29-36. [CrossRef] [PubMed]

13. Zogbi, M.M., Jr.; Saito, E.; Zanin, H.; Marciano, F.R.; Lobo, A.O. Hydrothermal-electrochemical synthesis of nano-hydroxyapatite crystals on superhydrophilic vertically aligned carbon nanotubes. Mater. Lett. 2014, 132, 70-74. [CrossRef]

14. Liu, T.; Ding, X.; Yang, X.; Gou, Z.; Chen, J.; Feng, X. Effect of carbonization treatment on the morphology and microstructure of mesoporous bioactive glass/nanocrystalline hydroxyapatite nanocomposite. J. Non-Cryst. Solids 2014, 389, 104-112. [CrossRef]

15. Fan, Z.; Wang, J.; Wang, Z.; Li, Y.; Ran, H.; Niu, L.; Gong, P.; Liu, B.; Yang, S. One-pot synthesis of graphene/hydroxyapatite nanorod composite for tissue engineering. Carbon 2014, 66, 407-416. [CrossRef]

16. Lin, K.; Liu, P.; Wei, L.; Zou, Z.; Zhang, W.; Qian, Y.; Shen, Y.; Chang, J. Strontium substituted hydroxyapatite porous microspheres: Surfactant-free hydrothermal synthesis, enhanced biological response and sustained drug release. Chem. Eng. J. 2013, 222, 49-59. [CrossRef]

17. Piccirillo, C.; Pullar, R.C.; Costa, E.; Santos-Silva, A.; Pintado, M.M.E.; Castro, P.M.L. Hydroxyapatite-based materials of marine origin: A bioactivity and sintering study. Mater. Sci. Eng. C 2015, 51, 309-315. [CrossRef] [PubMed]

18. Scientific Comkittee on Consumer Safety (SCCS). Available online: http:/ /ec.europa.eu/health/scientific _committees/consumer_safety/index_en.htm (accessed on 16 October 2015).

19. Shuai, C.; Feng, P.; Cao, C.; Peng, S. Processing and Characterization of Laser Sintered Hydroxyapatite. Biotechnol. Bioprocess Eng. 2013, 18, 520-527. [CrossRef]

20. Jin, X.; Chen, X.; Cheng, Y.; Wang, L.; Hu, B.; Tan, J. Effects of hydrothermal temperature and time on hydrothermal synthesis of colloidal hydroxyapatite nanorods in the presence of sodium citrate. J. Colloid Interf. Sci. 2015, 450, 151-158. [CrossRef] [PubMed]

21. Liu, L.; Huang, J.; Feng, Y.; Liu, J.; Yu, X. Synthesis and characterization of ultra long nanofibrillar and hydroxyapatite powder. Adv. Powder Technol. 2015, 26, 428-433. [CrossRef]

22. Byrappa, K.; Adschiri, T. Hydrothermal technology for nanotechnology. Prog. Cryst. Growth Charact. Mater. 2007, 53, 117-166. [CrossRef]

23. Murakami, S.; Kato, K.; Enari, Y.; Kamitakahara, M.; Watanabe, N.; Ioku, K. Hydrothermal synthesis of porous hydroxyapatite ceramics composed of rod-shaped particles and evaluation of their fracture behavior. Ceram. Int. 2012, 38, 1649-1654. [CrossRef]

24. Chen, Z.; Fu, Y.; Cai, Y.; Yao, J. Effect of amino acids on the crystal growth of hydroxyapatite. Mater. Lett. 2012, 68, 361-363. [CrossRef]

25. Gao, S.; Sun, K.; Li, A.; Wang, H. Synthesis and characterization of hydroxyapatite nanofiber by chemical precipitation method using surfactants. Mater. Res. Bull. 2013, 48, 1003-1006. [CrossRef]

26. Yang, X.; Gao, X.; Gan, Y.; Gao, C.; Zhang, X.; Ting, K.; Wu, B.M.; Gou, Z. Facile Synthesis of Octacalcium Phosphate Nanobelts: Growth Mechanism and Surface Adsorption Properties. J. Phys. Chem. C 2010, 114, 6265-6271. [CrossRef]

27. Okada, M.; Furuzono, T. Low-temperature synthesis of nanoparticle-assembled, transparent, and low-crystallized hydroxyapatite blocks. J. Colloid Interf. Sci. 2011, 360, 457-462. [CrossRef] [PubMed]

28. Layrolle, P.; Ito, A.; Tateishi, T. Sol-Gel Synthesis of Amorphous Calcium Phosphate and Sintering into Microporous Hydroxyapatite Bioceramics. J. Am. Ceram. Soc. 1998, 81, 1421-1428. [CrossRef]

29. Bakan, F.; Laçin, O.; Sarac, H. A novel low temperature sol-gel synthesis process for thermally stable nano crystalline hydroxyapatite. Powder Technol. 2013, 233, 295-302. [CrossRef] 
30. Popescu, L.M.; Piticescu, R.M.; Rusti, C.F.; Maly, M.; Danani, A.; Kintzios, S.; Valero Grinan, M.T. Preparation and characterization of new hybrid nanostructured thin films for biosensors design. Mater. Lett. 2011, 65, 2032-2035. [CrossRef]

31. Popescu, L.M.; Rusti, C.F.; Piticescu, R.M.; Buruiana, T.; Valero, T.; Kintzios, S. Synthesis and characterization of acid polyurethane-Hydroxyapatite composites for biomedical applications. J. Compos. Mater. 2013, 47, 603-612. [CrossRef]

32. Vasile, E.; Popescu, L.M.; Piticescu, R.M.; Burlacu, A.; Buruiana, T. Physico-chemical and biocompatible properties of hydroxyapatite based composites prepared by an innovative synthesis route. Mater. Lett. 2012, 79, 85-88. [CrossRef]

33. Popescu, L.M.; Piticescu, R.M.; Antonelli, A.; Rusti, C.F.; Carboni, E.; Sfara, C.; Magnani, M.; Badilita, V.; Vasile, E.; Trusca, R.; et al. Recent advances in synthesis, characterization of hydroxyapatite/polyurethane composites and study of their biocompatible properties. J. Mater. Sci. Mater. Med. 2013, 24, 2491-2503. [CrossRef] [PubMed]

34. Popescu, M.L.; Piticescu, R.M.; Petrescu, Ş.; Zdrenţu, L.; Mihăilescu, I.; Socol, G.; Lojkowski, W. Biocompatibility of hydroxyl-apatite thin films obtained by pulsed laser deposition. Rev. Adv. Mater. Sci. 2004, 8, 164-169.

35. Williams, J.S.; Xiao, Y.; Brownell, I. Low $\mathrm{pH}$ reprograms somatic murine cells into pluripotent stem cells: A novel technique with therapeutic implications. Cancer Biol. Ther. 2014, 15, 675-677. [CrossRef] [PubMed]

(C) 2016 by the authors; licensee MDPI, Basel, Switzerland. This article is an open access article distributed under the terms and conditions of the Creative Commons by Attribution (CC-BY) license (http://creativecommons.org/licenses/by/4.0/). 